\title{
COMPUTATIONAL MODELLING OF THERMOMECHANICAL BEHAVIOUR OF CAST IRONS: EFFECT OF BOUNDARY CONDITIONS
}

\section{EVANGELIA NEKTARIA PALKANOGLOU, KONSTANTINOS P. BAXEVANAKIS AND VADIM V. SILBERSCHMIDT}

Wolfson School of Mechanical, Electrical and Manufacturing Engineering, Loughborough University, LE11 3TU, UK

Key words: CGI, Thermal loading, Unit cell, Boundary conditions.

\begin{abstract}
In this work, a microstructure-based modelling approach is employed to investigate the performance of cast irons under thermal loading. Cast irons have a complex microstructure with graphite particles of different shapes, sizes and orientations embedded in an iron matrix. As a result of the mismatch in coefficients of thermal expansion of constituents, even a purely thermal load can cause failure. To evaluate this behaviour, representative volume elements of cast-iron microstructures are studied using finite-element simulations. Specific inputs in the models are provided based on statistical analysis of SEM micrographs. Further, the influence of boundary conditions is discussed. The obtained results demonstrate that the failure in the examined unit cells is sensitive to the adopted modelling assumptions, as well as the boundary conditions.
\end{abstract}

\section{INTRODUCTION}

Cast irons form a group of ferrous alloys, which substantial alloying elements are iron, carbon and silicon. The fractions of carbon and silicon are ranging from 2 to $4 \% \mathrm{wt}$ (in the form of either graphite or carbide) and 1 to 3\%, respectively. Different shapes of graphitic inclusions appear in the microstructure of various types of cast iron. Very thin, worm-like graphite particles called flakes are detected in grey (flake) iron, spherical ones termed nodules are identified in ductile iron, and an intermediate of two types, named vermicular particles-in compacted graphite iron (Figure 1) [1]. Cast iron, thanks to its excellent thermomechanical properties as well as its high wear resistance and completive price is used widely in applications ranging from machinery to automotive parts.

Although being used extensively in industrial applications, failure of cast irons at the microscale is not yet fully comprehended. This is attributed to its complex microstructure, where graphite particles of different morphology coexist and are surrounded by a metallic matrix. These inclusions influence failure at the microscale, especially under thermal loading. Due to the mismatch in the coefficients of thermal expansion the two constituents and the brittle nature of graphite, particles cannot follow the deformation of the surrounding matrix material and debond from it [2]. This decohesion, combined with stress concentration at their sharp edges, often leads to initiation of microcracks, which can then coalesce and propagate along the interface between the particles and the metallic matrix, leading to total failure [2]. 


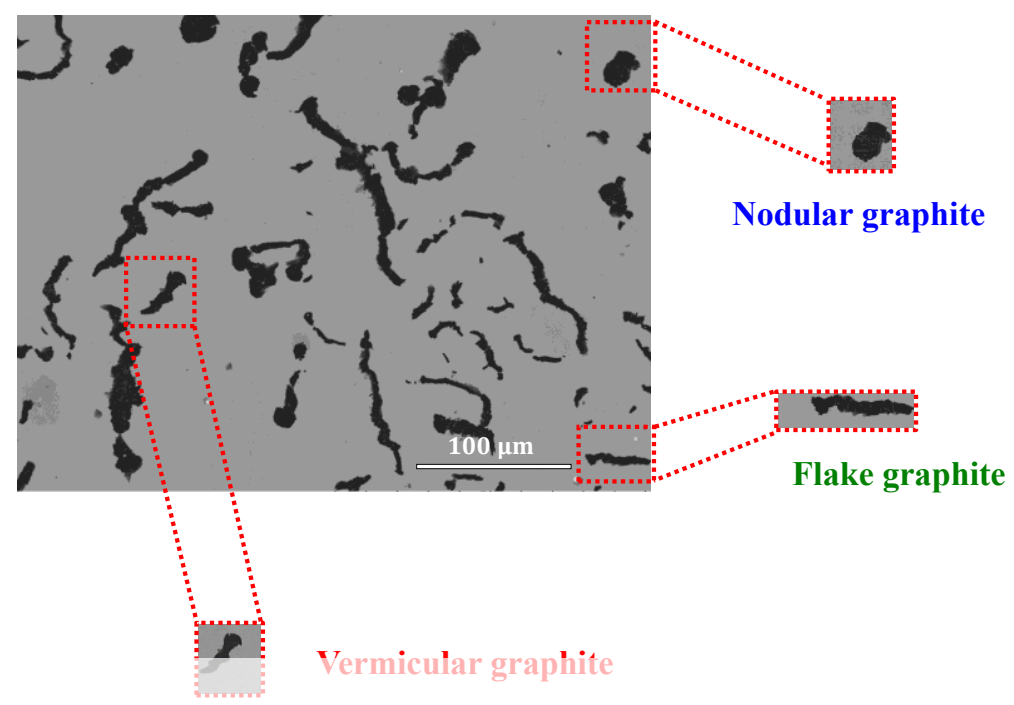

Figure 1: Microstructure of cast iron with different shapes of graphite particles

Although being used in various engineering applications, cast iron's first modelling approaches started in the 1970s. Existing modelling schemes for cast irons can be divided into macroscopic and micromechanical approaches, with focus mostly on either grey or ductile iron. First modelling ideas were based on a phenomenological macroscopic approach assuming, a

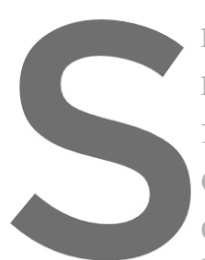
modification of a yiel microstructural features focuses on direct simula on experimental observations [6.7]. Recently, t] cast irons and crack-path prediction; however, loading has not been understood adequately yet.

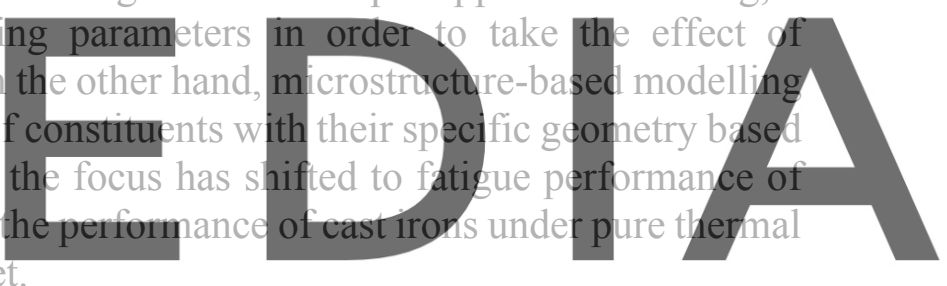

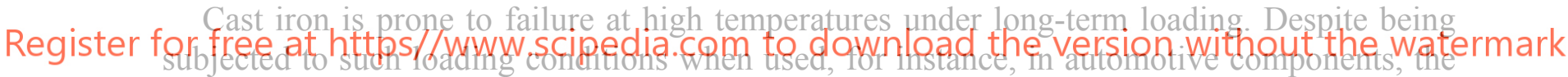
influence of pure thermal load was not considered in the existing models for cast irons. Also most modern modeliing strategies use three-dimensional (3D) formulations instead of twodimensional (2D) ones, which are computationally more expensive.

Therefore, in this paper, the effect of thermal loading on the performance of cast irons is investigated numerically, using both two-dimensional and three-dimensional models, in order to compare both the accuracy and the efficiency of the proposed assumptions. A microstructurebased approach is used herein with the required geometrical features obtained from statistical analysis of micrographs and constitutive parameters from in-house mechanical testing at various temperatures.

\section{METHODOLOGY}

\subsection{Microstructure characterisation}

A set of micrographs of compacted graphite iron (CGI) was captured using a scanning electron microscopy (SEM) and analysed with an image processing software ImageJ. Identification of different constituents was performed analysing their shades in greyscale, 
leading to the evaluation of morphological features such as the volume fraction of graphite, area and perimeter of particles. Statistical representation of the obtained results was employed for the development of a statistically equivalent unit cell $[8,9]$.

A proper selection of the particle shape in order to proceed with the measurements of their geometrical characteristics is a critical task. In this study, the ellipse was selected as it enables a better estimation of nodularity. Nodularity is a dimensionless parameter ranging from zero to one, with values higher than 0.80 describing a nodular shape, while lower ones indicate an elliptical one. Additionally, nodularity values lower than 0.20 correspond to very thin elliptical shapes that resemble needles and can be used to model flake particles. These geometrical parameters were evaluated based on pixel recognition, with an uncertainty equal to 0.5 pixels $/ \mathrm{mm}$. The results of statistical analysis of ImageJ are presented in Table 1 and Figure 2 [10].

Table 1: Minimum and maximum values of geometrical parameters of graphite particles in CGI [10]

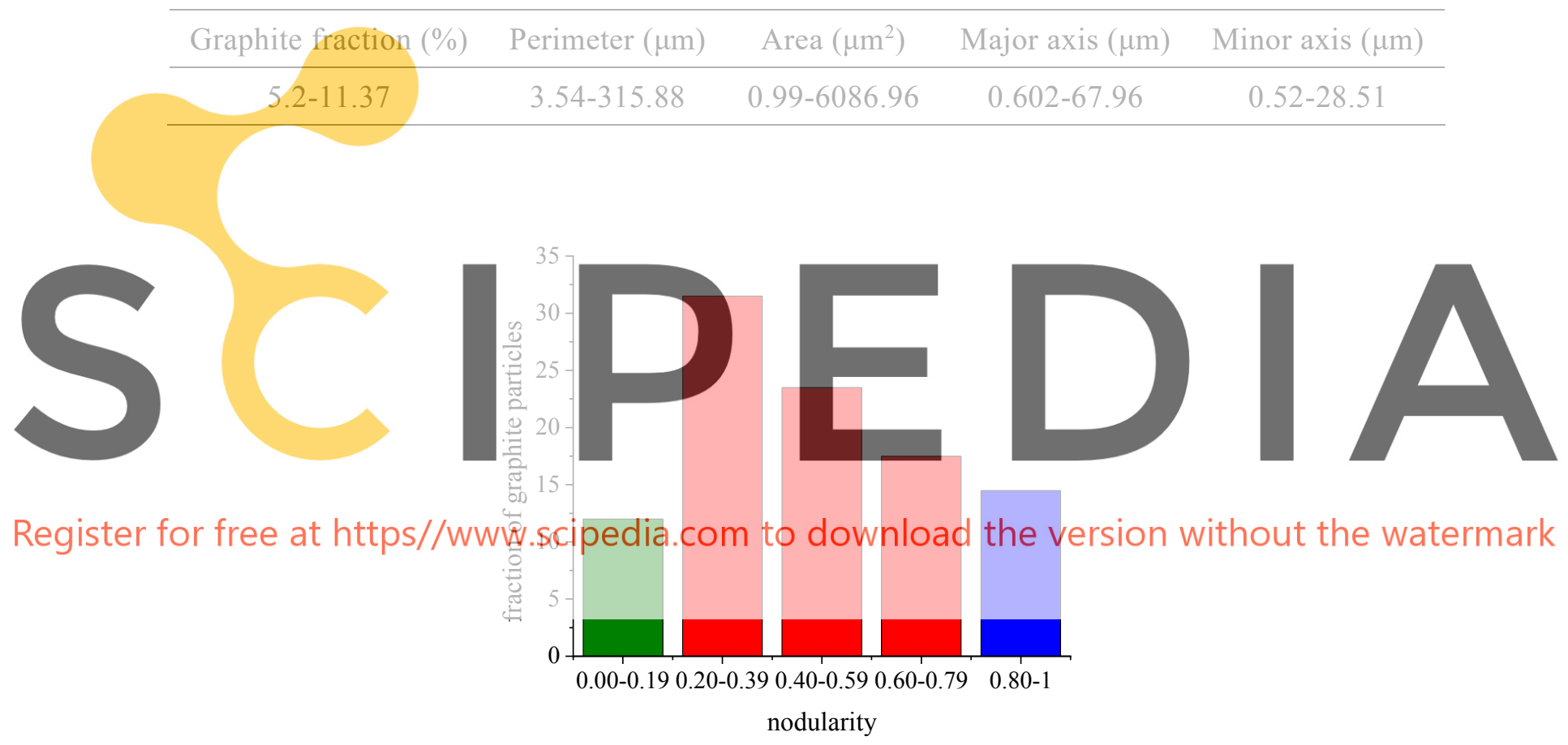

Figure 2: Average nodularity of graphite particles in volume fraction [10]

Apparently, most graphite particles exhibit average nodularity -0.20-0.59 (Figure 2), supporting the assumption that CGI has graphite particles of intermediate shape [11].

\subsection{Microstructure-based modelling}

Generally, a unit cell of a microstructured material in numerical simulations should enclose many inclusions [12]. However, due to CGI's complex microstructure, it is hard to study the effect of thermal loading on failure at the microscale, where interaction of graphitic inclusions takes place. This interaction alters the temperature, at which both decohesion and matrix 
plasticisation start, affecting the overall performance of CGI under thermal loading. Hence, a single-inclusion RVE was generated, assuming effective properties for the metallic matrix to account for the rest of the particles in the microstructure. This assumption is justified by evaluating the volume fraction of graphite, which is much lower than that of ferrite. Considering the results obtained from microstructural characterisation and following the abovementioned assumptions, a two-dimensional model was developed, comprising a square domain that represents the metallic matrix and an elliptical inclusion that accounts for graphite. While different graphite shapes appear in the microstructure in different fractions, vermicular inclusions were the most frequent, as indicated in Figure 2 (nodularity values in the range from 0.20 to 0.80 ) [10]. Hence, a vermicular inclusion was used in the simulations as representative of a general graphite inclusion. The geometrical characteristics of a two-dimensional RVE are presented in Figure 3, where the dimensions of inclusion were based on the results of microstructural characterisation. Specifically, the volume fraction of graphite was selected as 9\% (see Table 1), leading to an elliptical inclusion with a major axis equal to $50 \mu \mathrm{m}$ and a minor axis of $18 \mu \mathrm{m}$.
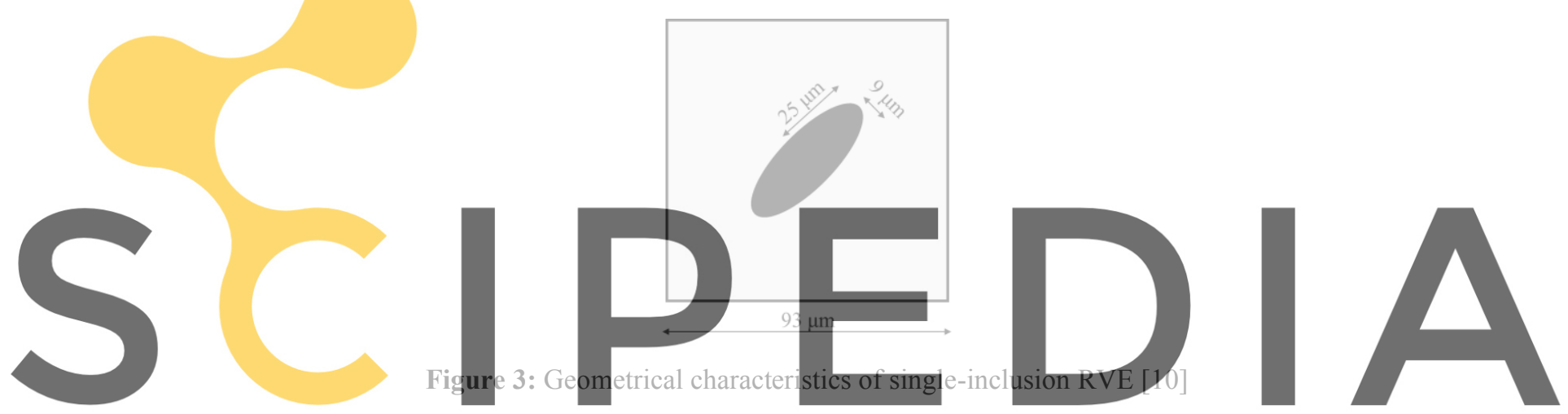

Further, the metallic matrix was considered as isotropic and ductile and, thus, an elastoplastic

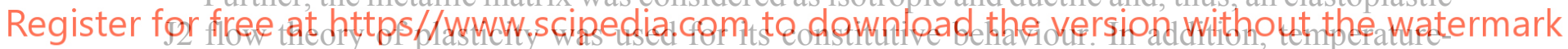

dependent data were used for the matrix since the objective was to study the behaviour of CGI

under pure thermal loading. Despite graphite's brittie nature, there is evidence that it exhibits a limited plastic deformation so that classical plasticity theory can be also used for its constitutive description [13-15]. The values of constitutive parameters for both constituents used in all simulations are depicted in Table 2. The constitutive parameters for the metallic matrix were assumed to be the effective ones, derived from mechanical tests of CGI specimens.

To consider the decohesion of graphite from the metallic matrix, a damage criterion was applied to the inclusion, with deletion of corresponding elements when a critical value was met. Damage was calculated in the finite-element code by assessing the magnitude of a damage variable $(D)$ at all Gauss points of a finite element. This variable accounts for the extent of stiffness reduction, after the onset of material degradation. Hence, an element was characterised as damaged after $D$ became non-zero in any of the four Gauss points and the element deletion followed the exceedance of the critical value at integration points. This deletion represents the loss of contact between the matrix and the inclusion after decohesion takes place. The threshold for the onset of damage was stress-based and equal to the yield stress of graphite since graphite behaves mostly elastically, and its plastic deformation is limited [10]. 
Table 2: Constitutive parameters for ferritic matrix and graphite inclusions

\begin{tabular}{|c|c|c|c|c|c|}
\hline \multicolumn{6}{|c|}{ Metallic matrix } \\
\hline $\begin{array}{l}\text { Yield } \\
\text { point } \\
(\mathrm{MPa})\end{array}$ & $\begin{array}{l}\text { Yield } \\
\text { strain }\end{array}$ & $\begin{array}{c}\text { Temperature } \\
\left({ }^{\circ} \mathrm{C}\right)\end{array}$ & $\begin{array}{l}\text { Young's } \\
\text { modulus } \\
(\mathrm{GPa})\end{array}$ & $\begin{array}{l}\text { Poisson's } \\
\text { ratio }\end{array}$ & $\begin{array}{c}\text { Coefficient } \\
\text { of thermal } \\
\text { expansion }\end{array}$ \\
\hline 323.95 & $0.209 \%$ & 50 & & & \\
\hline 316.84 & $0.195 \%$ & 150 & & & \\
\hline 301.18 & $0.225 \%$ & 300 & 150 & 0.25 & $1.2 \times 10^{-5}$ \\
\hline 265.92 & $0.178 \%$ & 400 & & & \\
\hline 257.71 & $0.179 \%$ & 500 & & & \\
\hline \multicolumn{6}{|c|}{ Graphite } \\
\hline 27.56 & $0.184 \%$ & 50 & 15.85 & 0.2 & $2.9 \times 10^{-6}$ \\
\hline
\end{tabular}

The two-dimensional unit cells were modelled with full-integration quadrilateral elements following either plane-stress or plane-strain formulation. Following a mesh-convergence study for both cases, a model was discretised into a freedom. A three-dimension dimensions to the twoelliptical inclusion was and performing a revolution dimensional unit cell indicated that a total
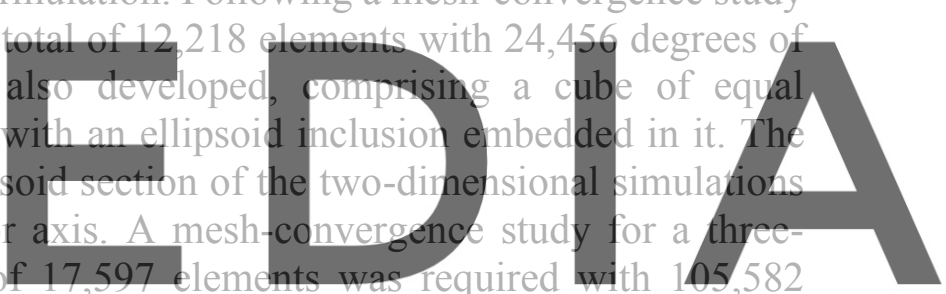
degrees of freedom

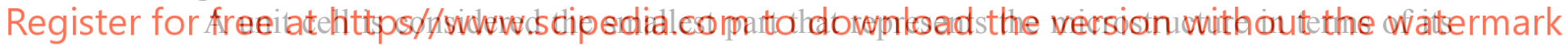
characteristics, assuming it has a regular pattern. Hence, periodic boundary conditions (PBCs) at the cell's edges were implemented to simulate accurately the deformation field [12]. PBCs guarantee that the external surfaces of the unit cell remain continuous during deformation. This ensures that every single unit cell exhibits the same deformation and neither overlaps nor separates from the surrounding unit cells. Considering any two points $x$ and $x+d$ lying on opposite edges of a unit cell of dimension $d$, the periodic boundary conditions on them are expressed as [16]

$$
\begin{gathered}
u(x+d)=u(x)+\bar{\varepsilon} \cdot d, \\
t(x+d)=-t(x),
\end{gathered}
$$

where $u$ and $t$ are the displacement and the surface traction, respectively, and $\bar{\varepsilon}$ is the average infinitesimal strain over the volume element, which is mostly defined externally.

Finally, pure thermal loading was used for all simulations to study the influence of increasing temperature on decohesion. CGI is prone to thermal loading due to its heterogeneous nature, while high-temperature conditions are generally observed in most of its engineering 
applications. In simulations, the loading was applied as a uniform field to the entire unit cell, and the temperature of the material increased from $25^{\circ} \mathrm{C}$ to $500{ }^{\circ} \mathrm{C}$.

\section{RESULTS}

\subsection{D modelling approach}

A comparison between unit cells modelled under either plane-strain or plane-stress conditions was performed to study the effect of these assumptions on the performance of CGI under thermal loading. The evolution of plastic zone for a single vermicular inclusion under former conditions is depicted in Figure 4(I). All graphs are plotted in the undeformed shape, with the graphitic inclusion removed so that the distributions of both stresses and strains are distinct. It is noted that plasticisation appeared at $218^{\circ} \mathrm{C}$ at the circumference of the inclusion (Figure 4(I)(a)). At $320^{\circ} \mathrm{C}$, although the entire matrix area was plasticised, the plastic strains around the circumference of the inclusion were about two to three times higher than the average one, around 0.0015 (Figure 4(I)(b)). A further increase by $100{ }^{\circ} \mathrm{C}$ caused the area with higher plastic strains between 0.0020 to 0.0025 to expand, covering almost $60 \%$ of the unit cell, whereas in the rest of the domain the plastic strain did not exceed 0.0020 (Figure 4(I)(c)). At $500{ }^{\circ} \mathrm{C}$, the high-strain area with plastic strains above 0.003 , was located around the inclusion covering almost $35 \%$ of the unit cell, whereas the plastic strain in the rest of the volume ranged from 0.0025 to 0.0029 (Figure 4(I)(d)).
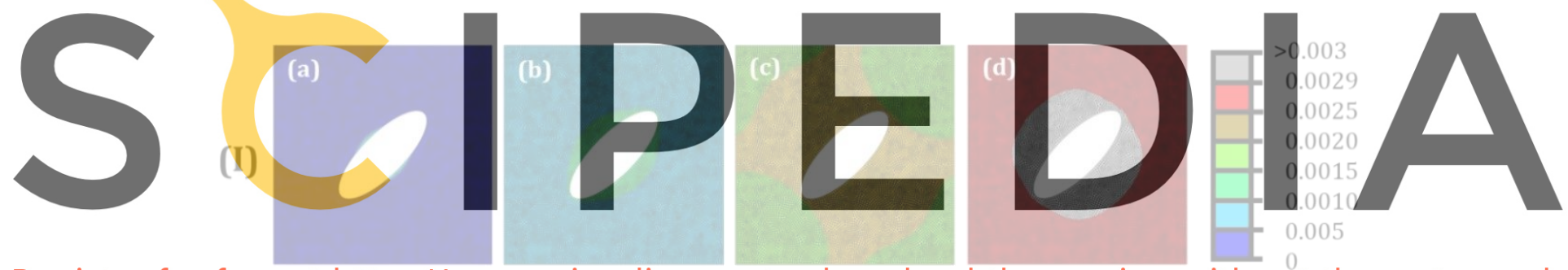

Register for free at hittps//www.scipedia.com th
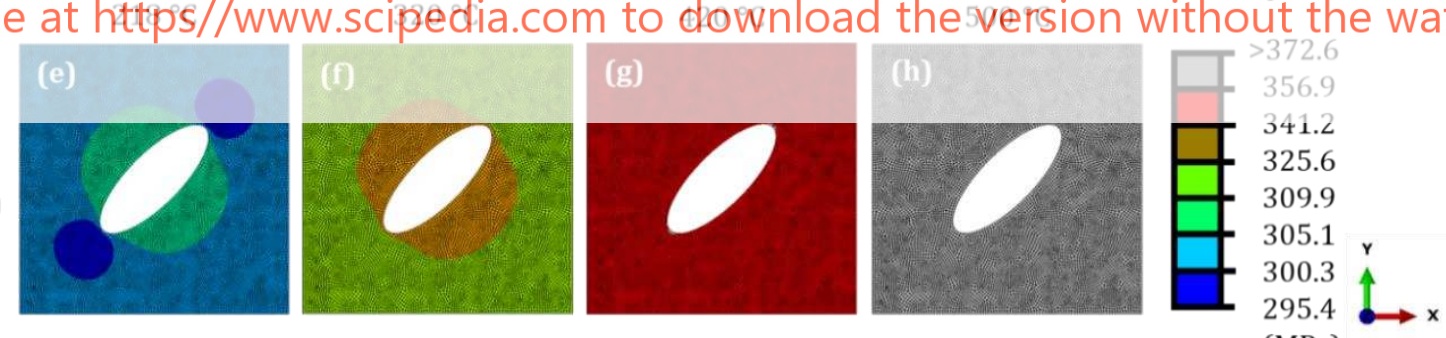

(MPa)

Figure 4: (I) Evolution of plastic zone in matrix for plane strain conditions. Equivalent plastic strain is depicted.

(II) von Mises stress distribution at the same temperatures is presented.

In Figure 4(II) the von Mises stress distributions are presented for the same temperature levels. At the onset of matrix plasticisation, the von Mises stresses ranged from $295 \mathrm{MPa}$ to 309 MPa (Figure 4(II)(a)). At $320^{\circ} \mathrm{C}$, the von Mises stresses reached $341 \mathrm{MPa}$ around the circumference of the inclusion, whereas in the rest of the unit cell did not exceed $325 \mathrm{MPa}$ (Figure 4(II)(b)). A further increase of temperature by $100{ }^{\circ} \mathrm{C}$ led to a uniform stress distribution of around $356 \mathrm{MPa}$ (Figure 4(II)(c)) throughout the unit cell. This trend was also observed at 
$500{ }^{\circ} \mathrm{C}$ where stresses exceeded $372 \mathrm{MPa}$ (Figure 4(II)(d)).

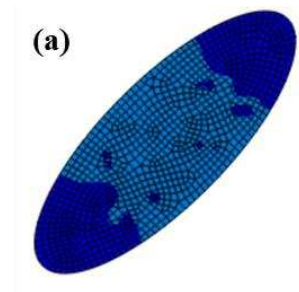

$215^{\circ} \mathrm{C}$

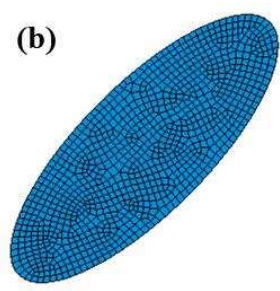

$320{ }^{\circ} \mathrm{C}$

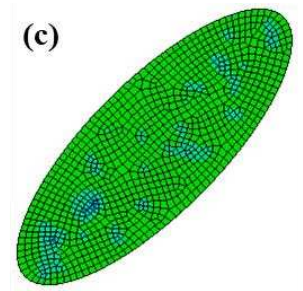

$420{ }^{\circ} \mathrm{C}$

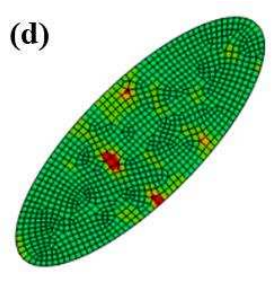

$500{ }^{\circ} \mathrm{C}$

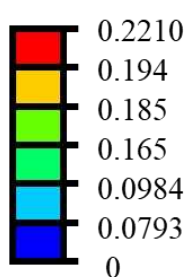

0

Figure 5: Damage evolution in graphite for plane strain conditions

The initiation of damage in graphite under plane-strain conditions was reported at $215^{\circ} \mathrm{C}$ (Figure 5), slightly before matrix plasticisation. The degradation of graphite started in the middle part of the inclusion, whereas the rest of the material remained undamaged (Figure 5(a)). At $320^{\circ} \mathrm{C}$, the entire inclusion was damaged, and the material degradation was uniform (Figure 5(b)). A further increase enhanced the degradation, which remained mostly uniform (Figure $5(c),(d))$.
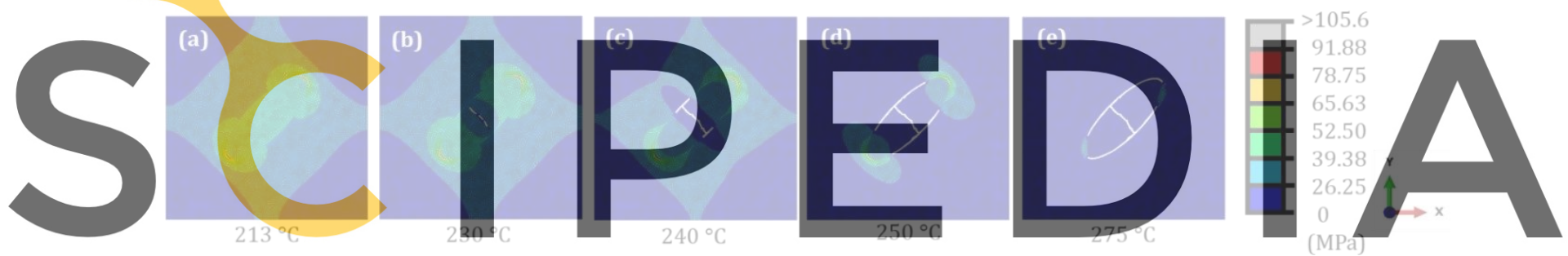

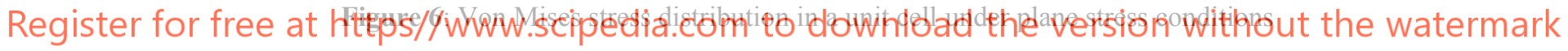

The von Mises stress distribution for a unit cell with a single vermicular inclusion under plane-stress condition is shown in Figure 6. Here, the onset of damage in graphite and its further evolution can be also observed (white lines). A unit cell under this condition exhibited no matrix plasticisation; therefore, the distribution of plastic strains is depicted in this case. At $213{ }^{\circ} \mathrm{C}$, stress concentrated around the edges of the inclusion with stresses reaching $52 \mathrm{MPa}$ (Figure 6), whereas the rest of the unit cell develops stresses below $39 \mathrm{MPa}$. This stress was low compared to the yield point around this temperature $310 \mathrm{MPa}$ (Table 2). At $230^{\circ} \mathrm{C}$, the stress distribution remained the same in the matrix material, with some stress decrease observed inside the inclusion. This is attributed to the removal of graphite elements causing a stress redistribution. At $240{ }^{\circ} \mathrm{C}$, a further decrease in stresses was found, as new elements inside the inclusion were deleted. At $250^{\circ} \mathrm{C}$, almost the entire circumferential layer of elements of the graphitic inclusion was removed, causing a stress concentration only its edges, with the entire matrix areas and the inclusion demonstrating very low stresses. Finally, at $275^{\circ} \mathrm{C}$, only a few elements of the circumferential layer were still present; the graphitic inclusion was mostly unstressed as the deletion of elements separated from the matrix

It is evident that the thermomechanical behaviour of CGI was affected by the assumptions 
considered in each model. With plane-strain assumption, matrix plasticisation was observed, whereas for the plane-stress formulation no plastic deformations in the matrix was reported. This is mainly attributed to the vanishing out-of-plane components of the stress tensor, especially $\sigma_{z z}$. For the plane-strain condition, $\sigma_{z z}$ had the highest value compared to the other two normal components, $\sigma_{x x}$ and $\sigma_{y y}$. Therefore, its contribution to the von Mises stress caused the appearance of plastic deformations in the matrix.

On the other hand, when assuming the plane-stress condition the graphite experienced a total degradation at the interface with most of its elements removed below $500{ }^{\circ} \mathrm{C}$. However, this was not the case for a unit cell under the plane-strain condition, where the damage of graphite was relatively low. Obviously, plasticisation and damage were both mechanisms of stress relief in the unit cell and each of them depended on the realisation of the other.

\subsection{D modelling approach}

In results of 3D numerical simulations, von Mises stresses of a unit cell with an embedded vermicular inclusion were below the corresponding yield stress at every temperature level (see Figure 7 and Table 2), hence no plastic deformation was reported. At temperatures up to 400 ${ }^{\circ} \mathrm{C}$ higher stresses were developed in the matrix material around the inclusion. At $408{ }^{\circ} \mathrm{C}$, the areas in the vicinity of the edges of the inclusion developed the highest stresses. Finally, at 500 ${ }^{\circ} \mathrm{C}$, stresses at the interface reached $157 \mathrm{MPa}$ in the main body with $189 \mathrm{MPa}$ at the edges.

Comparing results for the three-dimensional model and those for the two-dimensional one

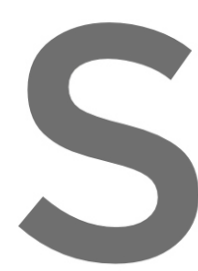
discussed previously, inclusion, either matrix developed in both graph behaviour of the entire volume element. Furth condition were between those for two cases:

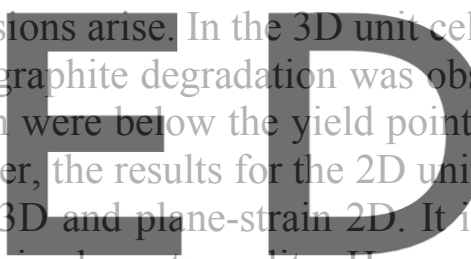
modelling approach should be preferred, as it is closer to reality. However, if a 2D model is selected to reduce computational cost, the plane-stress condition is recommended, as it provides

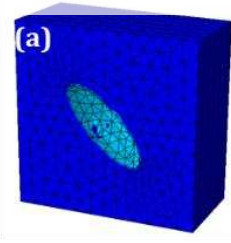

$108^{\circ} \mathrm{C}$

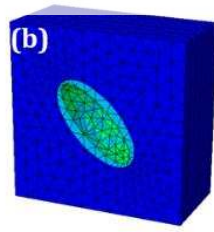

$208{ }^{\circ} \mathrm{C}$

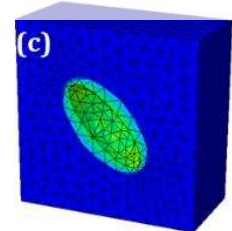

$308^{\circ} \mathrm{C}$

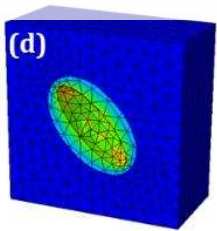

$408^{\circ} \mathrm{C}$

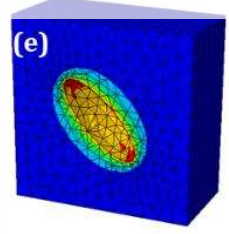

$508^{\circ} \mathrm{C}$

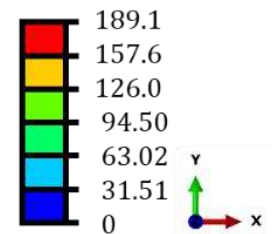

(MPa)

Figure 7: Von Mises stress distribution in 3D unit cell with embedded vermicular inclusion (inclusion is removed in figures)

\subsection{Effect of boundary conditions}

The effect of boundary conditions in both two-dimensional and three-dimensional modelling approaches is discussed in this section. Apart from the PBCs fully fixed and pinned ones were studied to compare the influence of boundary conditions on the onset of matrix plasticisation and graphite degradation. Both fixed and pinned boundary conditions were applied at all edges of the unit cells. The results of this comparison are presented in Table 3, where $T_{c}^{d}$ denotes the 
degradation-initiation temperature and $T_{c}^{p l}$ is the matrix-plasticisation temperature. It is noted that the periodic boundary conditions affected both the temperature of matrix plasticisation and graphite degradation. Initiation of plastic deformation in matrix material and damage in graphite took place under the plain-strain condition at a lower temperature. for both fixed and pinned BCs, Under plane-stress condition and either fully fixed or pinned boundary conditions, plastic deformations were developed in the matrix, while for a periodic unit cell there was no evidence of plasticisation. Graphite degradation was also affected by the different boundary conditions and occurred at considerably lower temperatures, for fixed and pinned boundary conditions. Finally, the application of either fixed or pinned boundary conditions at the edges of a threedimensional unit cell, caused both matrix plasticisation and graphite degradation, phenomena that not observed for PBCs in the 3D model.

Table 3: Effect of different boundary conditions for three different modelling approaches.

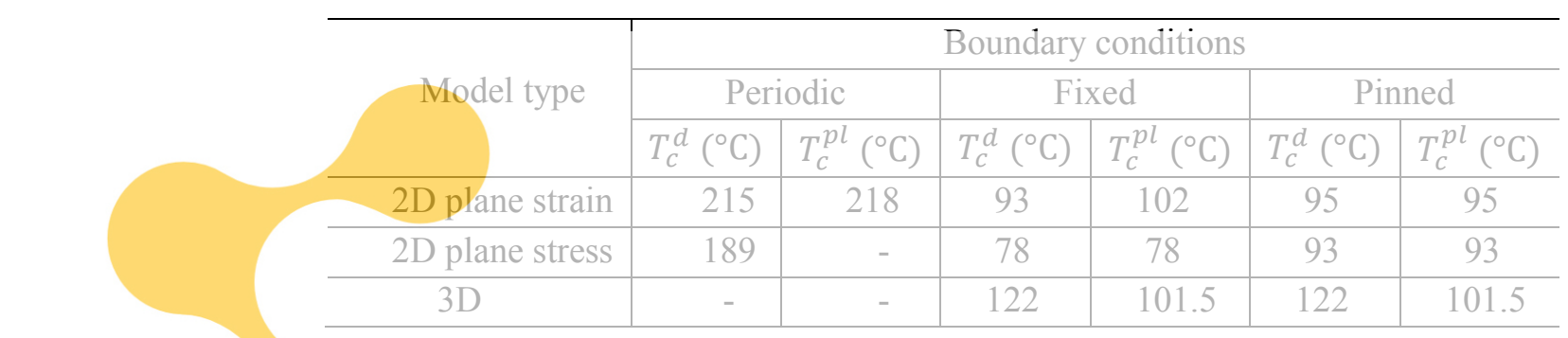
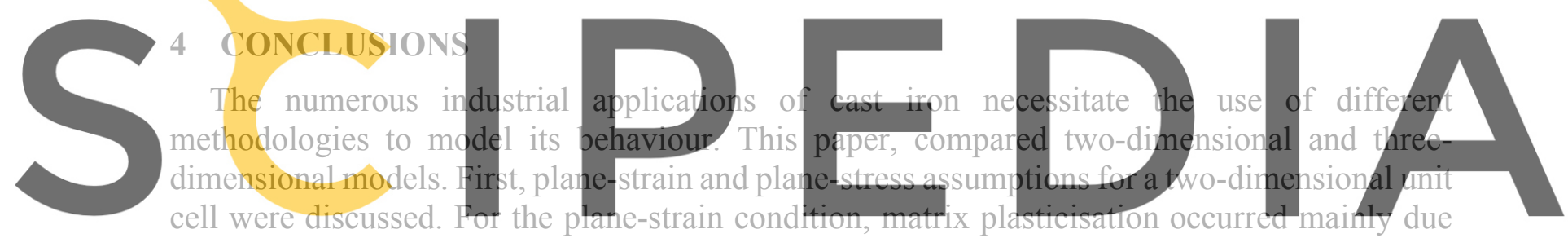

to the out-of-plane stress component. On the other hand, assuming the plane-stress conditions,

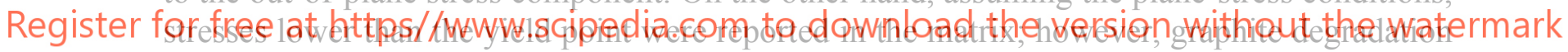

took place. When generating a three-dimensional unit cell, a more realistic stress profile was

obtained leading to a more accurate description of material behaviour under thermal loading. In this case, neither matrix plasticisation nor graphite degradation were observed, reinforcing the hypothesis that both phenomena might appear after several thermal cycles. It is also important to mention that a three-dimensional unit cell should be preferred (instead of a twodimensional one) thanks to its accuracy in geometrical representation of the analysed microstructure. Alternatively, a two-dimensional domain under plane-stress condition could be satisfactory for traction-free surfaces generally; its results were close to those of the threedimensional models.

Further, the effect of boundary conditions was studied. They affected both matrix plasticisation and graphite degradation for all the three model types examined. When altering boundary conditions to fixed or pinned for a two-dimensional unit cell, both phenomena occurred earlier, whereas in the three-dimensional model, they were not observed in the case of periodic boundary conditions. This trend is attributed to the fact that both fixed and pinned boundary conditions constrain the edges of the model, preventing it from expanding freely as the temperature increases. 
In conclusion, the results obtained for the influence of different modelling assumptions and boundary conditions on the thermomechanical performance of cast irons, allows further research on the effect of those assumption for more complex cases, e.g. with interaction between particles, orfor thermal cycling.

\section{REFERENCES}

[1] C. H. Lim and B. C. Goo, "Development of compacted vermicular graphite cast iron for railway brake discs," Met. Mater. Int., vol. 17, no. 2, pp. 199-205, 2011, doi: 10.1007/s12540-011-0403-x.

[2] G. Nicoletto, L. Collini, R. Konečná, and P. Bujnová, "Strain Heterogeneity and Damage Localization in Nodular Cast Iron Microstructures,” Mater. Sci. Forum, vol. 482, pp. 255-258, 2009, doi: 10.4028/www.scientific.net/msf.482.255.

[3] H. E. Hjelm, "Yield surface for grey cast iron under biaxial stress," Trans. ASME, vol. 3, pp. 465-472, 1994.

[4] B. L. Josefson, U. Stigh, and H. E. Hjelm, "A Nonlinear Kinematic Hardening Model for Elastoplastic Deformations in Grey Cast Iron," J. Eng. Mater. Technol., vol. 117, no. 2, 1995

[5] P. V. McLaughlin and R. E. Frishmuth, "Failure Analysis of Cast Irons Under General Three Dimensions Stress State," no. January, pp. 69-75, 1976.

[6] T. Andriollo, J. Thorborg, and J. Hattel, "The influence of the graphite mechanical properties on the constitutive response of a ferritic ductile cast iron - a micromechanical FE analysis," COMPLAS XIII Proc. XIIInt. Conf. Comput. Plast. Fundam. Appl., pp. 632-641, 2015.

[7] T. Andriollo, J. Thorborg, N. Tiedje, and J. Hattel, "A micro-mechanical analysis of thermo-elastic properties and local residual stresses in ductile iron based on a new anisotropic model for the graphite nodules," Model. Simul. Mater. Sci. Eng., 2016, doi: 10.1088/0965-0393/24/5/055012.

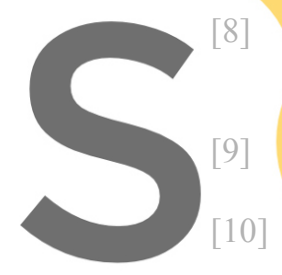
T. Kanit, S. Fores t, representative volu Struct., vol. 40, no. 1 P. Kanouté, D. P. Bo review," Arch. Com graphite iron: effect of ther

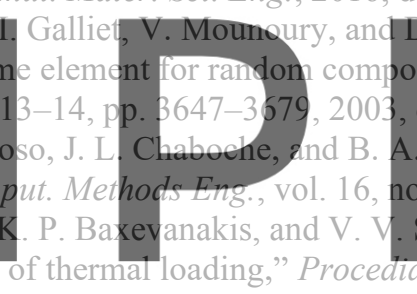
doi: 10.1016/j.prostr.2020.11.110
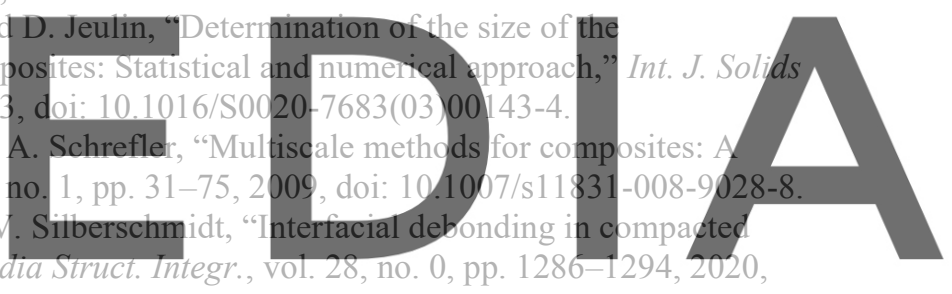

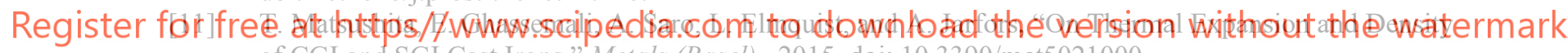
of CGI and SGI Cast Irons," Metals (Basel)., 2015, doi: 10.3390/met5021000.

[12] R. Hill, "Elastic properties of reinforced solids: Some theoretical principles," J. Mech. Phys. Solids, vol. 11, no. 5, pp. 357-372, 1963, doi: 10.1016/0022-5096(63)90036-X.

[13] T. Andriollo, J. Thorborg, N. S. Tiedje, and J. Hattel, "Modeling of damage in ductile cast iron - The effect of including plasticity in the graphite nodules," IOP Conf. Ser. Mater. Sci. Eng., vol. 84, no. 1, 2015, doi: $10.1088 / 1757-899 \mathrm{X} / 84 / 1 / 012027$.

[14] W. L. Greenstreet, G. T. Yahr, and R. S. Valachovic, "The behavior of graphite under biaxial tension," Carbon N. Y., vol. 11, no. 1, 1973, doi: 10.1016/0008-6223(73)90007-9.

[15] E. J. Seldin, "Stress-strain properties of polycrystalline graphites in tension and compression at room temperature," Carbon N. Y., vol. 4, no. 2, pp. 177-191, 1966, doi: 10.1016/0008-6223(66)90079-0.

[16] A. Drago and M. J. Pindera, "Micro-macromechanical analysis of heterogeneous materials: Macroscopically homogeneous vs periodic microstructures," Compos. Sci. Technol., vol. 67, no. 6, pp. 1243-1263, 2007, doi: 10.1016/j.compscitech.2006.02.031. 